\title{
IMPACT OF CLINICALLY IDENTIFIABLE INTRAPARTUM SENTINEL EVENTS ON SHORT TERM OUTCOME AFTER THERAPEUTIC HYPOTHERMIA IN INFANTS WITH HYPOXIC- ISCHEMIC ENCEPHALOPATHY
}

\author{
S. Sarkar ${ }^{1}$, I. Bhagat ${ }^{2}$, J.R. Bapuraj ${ }^{3}$, R.E. Dechert ${ }^{1}$, S.M. Donn ${ }^{1}$, J.D. Barks ${ }^{1}$ \\ ${ }^{I}$ Department of Pediatrics, Division of Neonatal-Perinatal Medicine, University of Michigan Health System, \\ ${ }^{2}$ Department of Pediatrics, St. Joseph Mercy Hospital, ${ }^{3}$ Department of Radiology, University of Michigan \\ Health System, Ann Arbor, MI, USA
}

Objective: To determine the impact of intrapartum sentinel events on short term outcome following therapeutic hypothermia.

Methods: Medical records of 77 infants $\geq 36$ weeks' gestation, who received hypothermia were reviewed. Some of these infants were delivered after a clinically identifiable intrapartum sentinel event (IISE). All surviving infants had brain MRI at 7 to 10 days of life. The primary outcome of neonatal death related to hypoxic-ischemic encephalopathy (HIE) with worsening multiorgan dysfunction despite maximal treatment was compared between infants born after an IISE $(n=39)$ and infants who did not (non-IISE, $n=38)$. The pattern of MRI abnormalities consistent with hypoxic-ischemic brain injury was also compared. Logistic regression analysis was used to determine which of the variables predicts the primary outcome.

Results: The two groups had similar Apgar scores, initial blood $\mathrm{pH}$, and early neurologic examination. Base deficit was more severe in the IISE group. Neonatal death and global injury on brain MRI with basal nuclei, cortical, and subcortical white matter lesions extending beyond the watershed areas in infants surviving beyond the neonatal period were also more frequent in infants from this group (IISE $23 \%$ versus non-IISE $2.6 \%, \mathrm{p}=0.014$, OR $11.1,95 \%$ CI $1.3-92.6$ and IISE $33 \%$ versus non-IISE $11 \%, \mathrm{p}=0.034$, OR 4.1, 95\% CI 1.1-14.9 respectively). Multivariate analysis identified IISE ( $\mathrm{p}=0.023$, OR 12.2, 95\% CI 1.4-105.8) to be independently associated with neonatal death.

Conclusions: An IISE is associated with an increase in neonatal death and more severe injury on brain MRI, even after hypothermia. 